\title{
The effects of Hypericum perforatum on hepatic ischemia- -reperfusion injury in rats
}

\author{
Aydin $\mathrm{A}^{1}$, Sakrak $\mathrm{O}^{2}$, Yilmaz $\mathrm{TU}^{3}$, Kerem $\mathrm{M}^{2}$ \\ Gazi Üniversity, School of Medicine, Department of General Surgery, Ankara, Turkey. tonyutku@hotmail.com
}

\begin{abstract}
Background: Ischemia-reperfusion injury (IR) is associated with a high morbidity and mortality. Several agents have been used to protect the liver after IR. We aimed to investigated the effects of the Hypericum perforatum on IR of the liver.

Methods: A total of 62 wistar-albino male rats in 4 groups were used. Sham group (n: 8). Control group (IR, n: 18 ) was underwent partially liver ischemia and reperfusion (IR). Carboxymethyl cellulose group (CMC $n: 18)$ was given $0.5 \%$ carboxymethyl cellulose before IR for a week. Hypericum perforatum group (HP, n:18) was given $0.5 \%$ carboxymethyl cellulose supplemental the extract of Hypericum perforatum before IR for a week. Blood and liver samples were obtained before ischemia, and 1, 2, 4 hours after the reperfusion. AST, ALT, LDH, TNF- $\alpha$, IL-6, MDA and advanced oxidation protein products(AOPP) levels were determined in blood samples. Histological evaluation and tissue MDA, AOPP levels were determined.

Results: Blood levels of ALT, TNF- $\alpha$, IL-6 and MDA were significantly low in HP group compared with IR and CMC groups $(p<0.05)$. There was no difference between the liver injury scrores of IR and CMC groups $(p>0.05)$. Conslusion: These results indicate that $\mathrm{H}$. perforatum can protect the liver against IR. As antioxidative agent, Hypericum perforatum has both local and systemic protective effects in ischemia reperfusion injury (Tab. 1 , Fig. 4, Ref. 31). Text in PDF www.elis.sk.

Key words: Hypericum perforatum, St. John's wort, ischemia-reperfusion, oxidative stress.
\end{abstract}

Ischemia followed by reperfusion which occurs during liver transplantation, sepsis, or hepatic pedicle clamping during liver surgery initiates injury including several metabolic and structural damages $(1,2)$. Free oxygen radicals, leukocyte migration and activation, microcirculatory abnormalities, sinusoidal endothelial cell damage, activation of the coagulation cascade, Kupffer cell activation due to release of inflammatory cytokines and proteolytic enzymes are the related factors for the damages (2-4). Several agents targeting these factors have been studied recently (2-7). Oxygen free radicals, produced on reperfusion play a triggering and critical role in the injury caused by ischemia-reperfusion (IR). The antioxidants are the target for the treatment because the triggering mechanism is the free oxygen radicals,

Hypericum perforatum L. (Hypericaceae) (HP) known as St. John's wort has been used since ancient times to threat different disorders. Still, HP is being used for wound healing in rural part of Turkey. HP contains hypericin, hyperforin, flavonoids and flavonoid derivatives, xanthone derivatives, and biapigenin. These

\footnotetext{
${ }^{1}$ Ankara Keciören Education and Research Hospital, Department of General Surgery, Keciören, Ankara, Turkey, ${ }^{2}$ Gazi University School of Medicine, Deparment of General Surgery, Beşevler, Ankara, Turkey, and ${ }^{3}$ Kocaeli University School of Medicine, Deparment of General Surgery, Umuttepe, Kocaeli, Turkey

Address for correspondence: T.U. Yilmaz, MD, Kocaeli University School of Medicine, Department of General Surgery, Umuttepe, Kocaeli, 41380, Turkey
}

active components demonstrate potential antioxidant activity by free radical scavenging, inhibition of lipid peroxidation, activation of signal transducers $(8,9)$.

Therefore, it seems posible that the administration of $\mathrm{Hy}$ pericum perforatum might protect the liver against the ischemia reperfusion injury. We aimed to evaluate the antioxidative effects of $\mathrm{HP}$ in rat liver $\mathrm{I} / \mathrm{R}$ model.

\section{Material and method}

\section{Animals and experimental protocol}

The experiment was performed under standart conditions in compliance to Local Ethical Committee at Gazi University, Turkey (G.U.ET-08.052). Sixty-two male Wistar-albino rats which weighted 200-275 g, were used. Only water was provided in the $12 \mathrm{~h}$ preceding the experiments. After 10 days adaptation to laboratory conditions, the animals were divided into four groups: sham group, control group (IR), carboxymethyl cellulose (CMS) group, and Hypericum perforatum group (HP). The groups were composed of 18 rats except group 1 which had 8 rats. CMS group received $4 \mathrm{ml} / \mathrm{kg} /$ day CMS (0.5) solution and HP group recieved $400 \mathrm{mg} / \mathrm{kg} /$ day HP extract in $0.5 \%$ CMS solution for a week before the operation. We chose the dose which has been shown to be effective in the previous studies (10-12).

The raw materials were collected from the village and were authorized as the authentic Hypericum perforatum by professor Mecit VURAL, Gazi University and still stored in Gazi Univer- 
sity Pharmacology Department Herbarium (No: 242). The plants with their flowers were dried in the shadow and powdered. Every 100 gr plant powder was mixed with $2 \mathrm{~L}$ ethanol (96\%) for half an hour every day for 4 days. The extracts with ethanol were concentrated under low pressure at $50{ }^{\circ} \mathrm{C}$ at rotavapor. And then the materials were dried in vacuum desiccator under low pressure. By this way plant extracts with ethonal were achieved. In order to feed the animals with HP extracts, they were dissolved in the $0.5 \%$ carboxymetyl cellulose in order to achieve $10 \%$ saturated HP solutions.

All rats were anesthetized with $45 \mathrm{mg} / \mathrm{kg}$ ketamin hydrochloride and $5 \mathrm{mg} / \mathrm{kg}$ xylazine intraperitoneally. After the abdomen was shaved and disinfected, a midline incision was performed. In the rats of sham group, $4 \mathrm{ml}$ blood and 3 gr liver sample were taken for biochemical and histological evaluation and rats were sacrified. Six rats from each IR, CMS and HP groups, after obtaining $2 \mathrm{ml}$ blood from vena cava and $2 \mathrm{gr}$ tissue sample from left liver sample, were sacrified. Remaining rats were used for the IR. After exposing the afferent and efferent blood vessels, ischemia was carried out for left and medial lobes of liver (70 \%) by clamping for 45 min with microvascular "bulldog" clamp as described in the study of Kerem et al (13). Forty five minutes later, the ischemic liver was reperfused by opening the clamp. Blood and liver samples were taken out from 6 rats in each group on the 1st, 2nd and 4 th hours. Rats were sacrified after the sampling.

\section{Liver function tests}

Blood samples were centrifuged immediately at $1500 \mathrm{rpm}$ for $10 \mathrm{~min}$ and then serum AST, ALT and LDH levels were assayed by using autoanalyzer (Abbott Architect ci 16200).

\section{Measurement of plasma cytokine levels}

Blood samples were centrifuged immediately at $1500 \mathrm{rpm}$ for $10 \mathrm{~min}$ and then serum samples were stored at $-80{ }^{\circ} \mathrm{C}$ until the analysis. The levels of tumor necrosis factor (TNF- $\alpha$ ) and interleukin 6 (IL-6) were evaluated in the serum by the commercial kits (IL-\& Eliza (BMS 625) and TNF- $\alpha$ Eliza (KRC 3011)).

\section{Tissue malondialdehyde (tMDA) measurement}

Levels of MDA in the liver tissues were determined as an index of lipid peroxidation, as described by Okhawa et al. (14). Liver tissues were homogenized in $50 \mathrm{mM}$ Tris- $\mathrm{HCl}(\mathrm{pH} 7.4)$ solution. An liquid $(50 \mu \mathrm{L})$ of the homogenate was added to a reaction mixture containing $50 \mu \mathrm{L}$ of $8.1 \%$ SDS, $375 \mu \mathrm{L} 20 \%$ acetic acid (pH 3.5), $375 \mu \mathrm{L}$ thiobituric acid, and $150 \mu \mathrm{L}$ distilled water. Samples were then boiled for $60 \mathrm{~min}$ at $95{ }^{\circ} \mathrm{C}$ and were cooled. Then samples were vortexed by $250 \mu \mathrm{L}$ distilled water and $1.250 \mathrm{ml} \mathrm{n}$-butanol/ piridine $(15: 1 \mathrm{v} / \mathrm{v})$. The samples were centrifugated at $4000 \mathrm{rpm}$ for $60 \mathrm{~min}$. The absorbance of the supernatant was measured by the spectrophotometry at $650 \mathrm{~nm}$.

\section{Plasma MDA (pMDA) measurement}

Plasma levels of MDA were determined by the method described by Yoshioka et al (15). The serum samples $(250 \mu \mathrm{L})$ were boiled with $1.250 \mathrm{ml} 20 \%$ trichloroacetic acid and $0.5 \mathrm{ml} 0.67 \%$ thiobarbituric acid for $30 \mathrm{~min}$. After cooling the samples were mixed with $2 \mathrm{ml} \mathrm{n}$-butanol, and centrifugated at $3000 \mathrm{rpm}$ for 5 min. Colored complex is detected by measurement of absorbance at $532 \mathrm{~nm} .1,1^{\prime} 3,3^{\prime}$-Tetramethoxypropane was used as a standart and the results were expressed as $\mathrm{nmol} / \mathrm{ml}$

\section{Measurement of plasma and tissue advanced oxidation protein products}

Plasma (pAOP) and tissue (tAOP) advanced oxidation protein products were determined by spectrophotometry as described bt Witko-Sarsat et al (16). Liver tissue samples were homogenized by $50 \mathrm{mM}$ Tris- $\mathrm{HCl}(\mathrm{pH} \mathrm{7.4)}$ in a cold enviroment. The tissue supernatans were obtained by centrifugation at $15000 \mathrm{rpm}$ for 15 min. Tissue supernatants and $200 \mu \mathrm{l}$ plasma samples were diluted by phosphate buffer saline at $1 / 5$ ratio. After mixing with $10 \mu \mathrm{l}$ potassium iodide and $20 \mu \mathrm{l}$ acetic acid, absorbance was measured at $340 \mathrm{~nm}$. Chloramine was used as a standart and the results were expressed as $\mathrm{mmol} / \mathrm{gr}$ for tissue and $\mu \mathrm{mol} / \mathrm{L}$ for plasma.

\section{Histopathological examination}

The liver biopsies were fixed in $10 \%$ formaline solution. Fivemicron-thick sections were cut from the parafin-embedded liver tissue specimens, routinely processed and stained with hematoxylin and eosin. A pathologist who was unaware of the animal groups evaluated the specimens by light microscopy. Histopathological analysis, based on the scoring system, was applied on all samples to determine the degree of cytoplasmic vacuolization, nuclear pycnosis, cytoplasmic hypereosinophilia, degeneration in hepatic cords, necrosis with polymorphonuclear leukocyte (PMNL) infiltration and hemorrhage. PMNL per unit area of sinusoidal endothelial cells (SEC) were counted.

Tab. 1. The levels of liver enzymes, cytokines, tMDA, pMDA, tAOP, pAOP, and number of PMNL per unit area in all groups.

\begin{tabular}{|c|c|c|c|c|}
\hline & Sham Group (mean \pm SD) & IR Group (mean \pm SD) & CMS Group (mean \pm SD) & HP Group (mean $\pm \mathrm{SD})$ \\
\hline$\overline{\mathrm{AST}}(\mathrm{IU} / \mathrm{mL})$ & $124.87 \pm 12.1$ & $572.2 \pm 283.6$ & $660.4 \pm 358.6$ & $414.3 \pm 179.0$ \\
\hline ALT (IU/mL) & $63.0 \pm 10.7$ & $750.3 \pm 430.6$ & $798.4 \pm 694.7$ & $286.7 \pm 161.6$ \\
\hline LDH (IU/mL) & $790.7 \pm 203.0$ & $2227.4 \pm 634.8$ & $2237.1 \pm 1001.2$ & $1200.6 \pm 1089.3$ \\
\hline $\mathrm{pMDA}(\mathrm{nmol} / \mathrm{ml})$ & $3.8 \pm 0.6$ & $8.0 \pm 1.7$ & $9.6 \pm 2.9$ & $5.3 \pm 1.1$ \\
\hline tMDA (nmol/gr) & $84.9 \pm 7.5$ & $153.1 \pm 19.4$ & $126.9 \pm 22.7$ & $94.0 \pm 18.8$ \\
\hline $\mathrm{pAOP}(\mu \mathrm{mol} / \mathrm{L})$ & $86.1 \pm 10.6$ & $331.9 \pm 206.8$ & $410.5 \pm 198.8$ & $270.7 \pm 74.6$ \\
\hline tAOP mmol/gr) & $1.8 \pm 0.7$ & $5.1 \pm 1.5$ & $6.1 \pm 1.5$ & $3.7 \pm 0.9$ \\
\hline IL-6 $(\mathrm{pg} / \mathrm{ml})$ & $14.7 \pm 4.7$ & $35.6 \pm 8.7$ & $31.3 \pm 6.9$ & $19.3 \pm 7.2$ \\
\hline Number of PMNL in unit ares & $1.37 \pm 0,5$ & $6,4 \pm 3,3$ & $5,4 \pm 3,2$ & $2,5 \pm 1,5$ \\
\hline
\end{tabular}




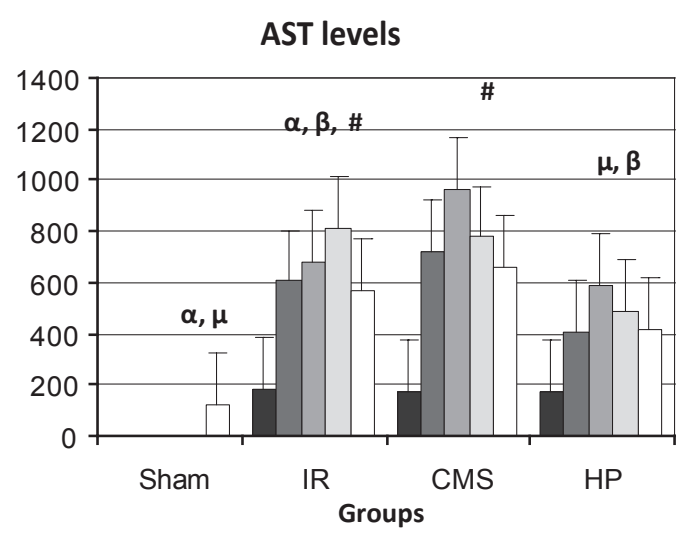

• Preisch $\square$ 1st hour $\square$ 2nd hour $\square$ 4th hour $\square$ Mean $\alpha: p=0.002 \quad \mu: p=0.084 \quad \beta: p=0.024 \quad \#: p=0.735$

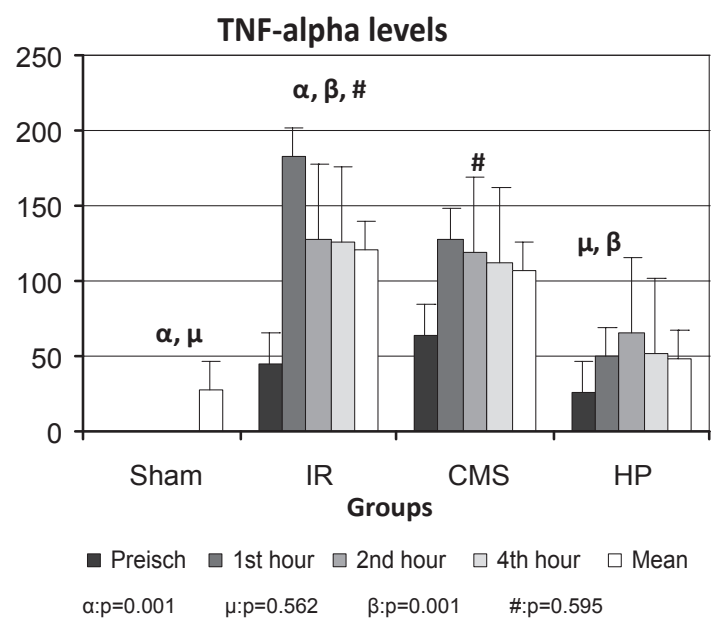

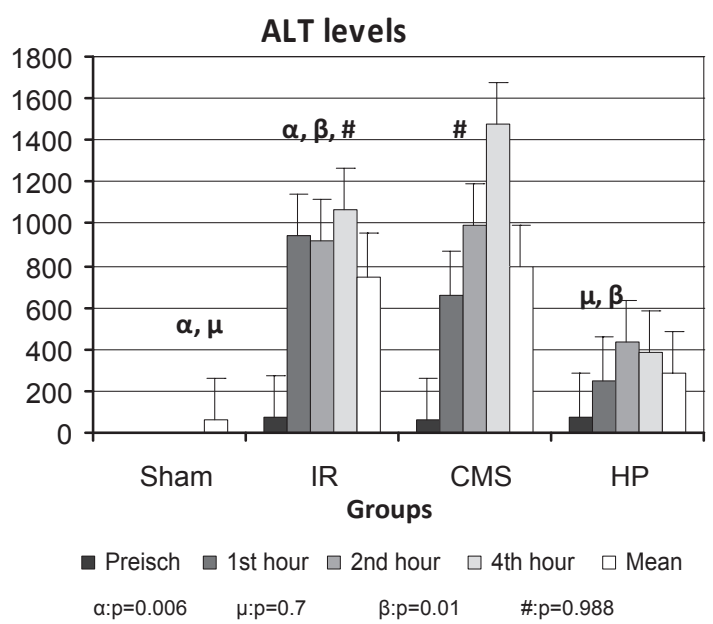

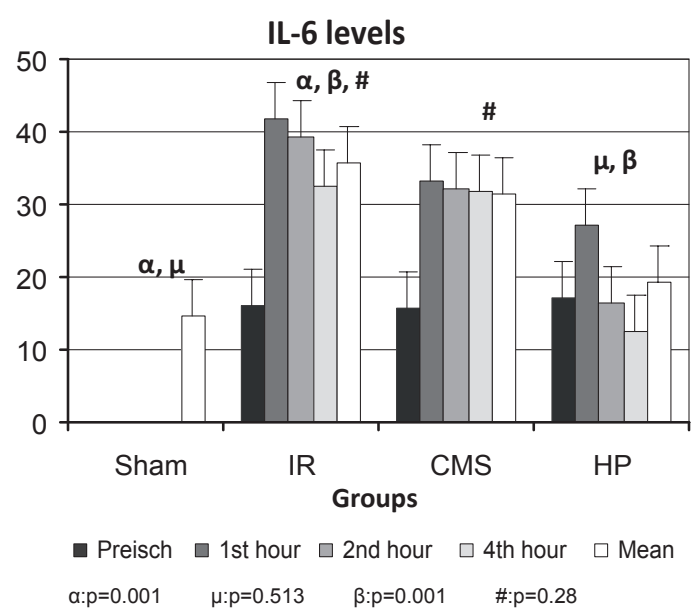

Fig. 1. The levels of liver enzymes and cytokines on different reperfusion hours were given. Comparison of mean level of liver enzymes and plasma cytokines among groups were shown ( $p$ values used for comparison of groups were pointed by $\alpha, \beta$, \#, $\mu$ ).

\section{Statistical analysis}

The data were expressed as the mean \pm S.D. and analysed with the Statistical Products and Service Solution package (SPSS for Windows, version 13.0, Chicago, IL). One-way analysis of variance (ANOVA) followed by Post Hoc Scheffe multi comparison test were used to compare the study groups. Nonparametric results were analysed by Kruskal-Wallis test and groups were compared with Mann-Whitney U test. Statistical significance was defined by a $p$ value less than 0.05 .

\section{Results}

There were no significant differences between groups in respect of levels of parameters measured in the preischemic period. For this reason comparison was performed according to the results obtained after reperfusion in study groups. There were significant differences between groups depending on all parameters according to One Way ANOVA test.

The mean values of AST, ALT, TNF- $\alpha$, IL-6, tMDA, LDH, pMDA, and tAOP levels in sham group and HP group were signifi- cantly lower than in CMS and IR groups $(\mathrm{p}<0.05)$ (Tab. 1, Figs 1 and 2). Although the difference between mean pAOP levels of sham and IR was significant, the difference between the mean pAOP levels of HP and IR was not significant (Fig. 3). However, when we reevaluated the levels of pAOP on the 1st, and 2 nd hours, it was seen that there was significant difference between HP and IR groups ( $p$ $=0.001)$. The difference between the mean AST, ALT, TNF- $\alpha$, IL6, tMDA, LDH, pMDA, pAOP, and tAOP levels of sham group and HP groups was not significant $(p>0.05)$ (Tab. 1, Figs 1-3).

Histological injury scores in sham group were significantly lower than in IR and CMS groups $(\mathrm{p}<0.05)$, however, not significantly different than in HP group $(p>0.05)$. Histological injury scores in HP group were significantly lower than in IR and CMS groups $(\mathrm{p}<0.05)$; on the other hand the difference between CMS and IR groups was not significant $(\mathrm{p}>0.05)$. There were diffuse grade-1 and grade-2 tissue injuries in CMS and IR groups (Fig. 4).

PMNL in per unit area of SEC in sham and HP groups were significantly lower than IR and CMS groups $(p<0.05)$. On the other hand the difference between IR and CMS and also the difference between sham and HP was not significant $(p>0.05)$. 


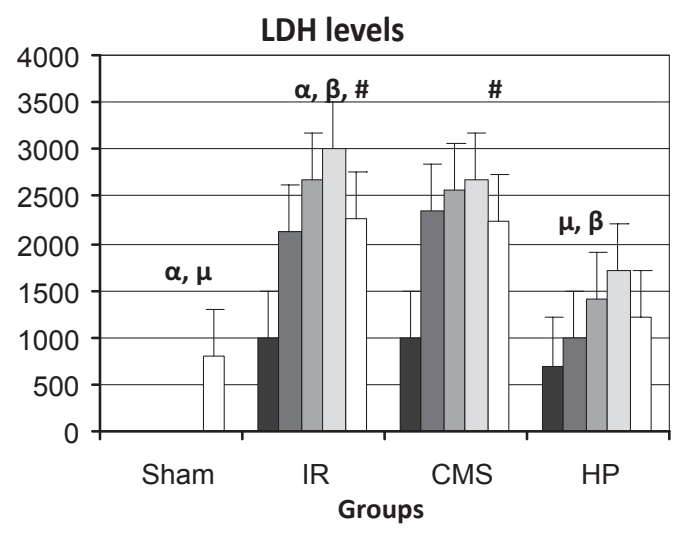

- Preisch $\square$ 1st hour $\square$ 2nd hour $\square$ 4th hour $\square$ Mean $\alpha: p=0.01 \quad \mu: p=0.1 \quad \beta: p=0.01 \quad \#: p=0.54$

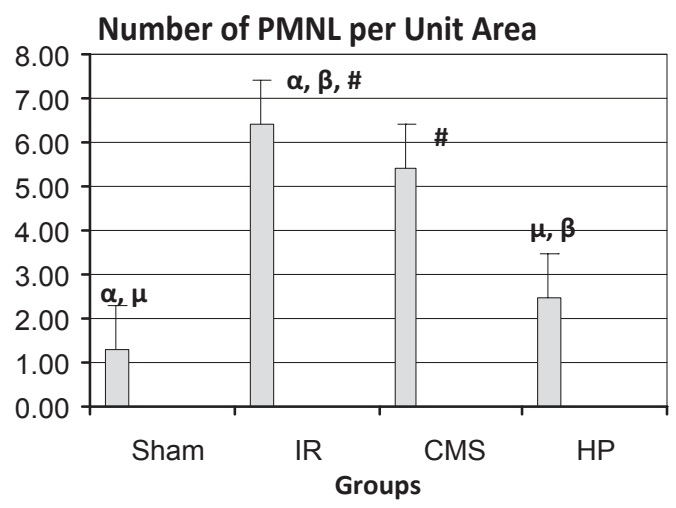

$\alpha: p=0.01 \quad \mu: p=0.1 \quad \beta: p=0.01 \quad \#: p=0.54$

Fig. 2. The levels of tissue AOP, MDA and plasma AOP, MDA on different reperfusion hours were given. Comparison of mean levels of tissue AOP, MDA and plasma AOP, MDA among groups were shown ( $p$ values used for comparison of groups were pointed by $\alpha, \beta$, \#, $\mu$ ).

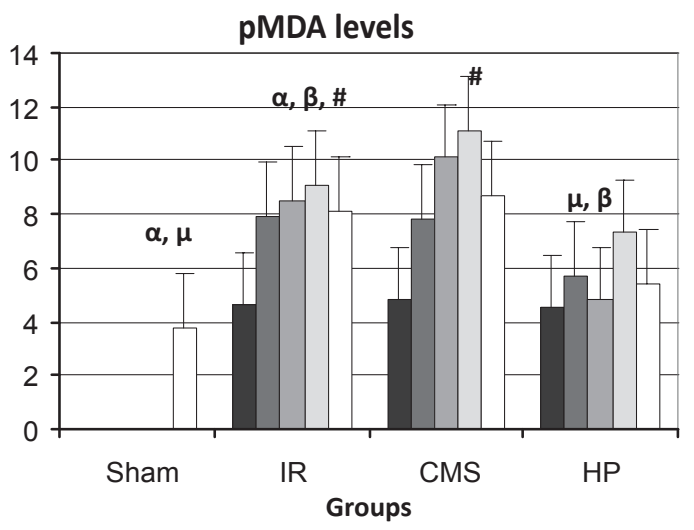

- Preisch $\square$ 1sthour $\square$ 2nd hour $\square$ 4th hour $\square$ Mean $\alpha: p=0.001 \quad \mu: p=0.324 \quad \beta: p=0.001 \quad \#: p=0.07$

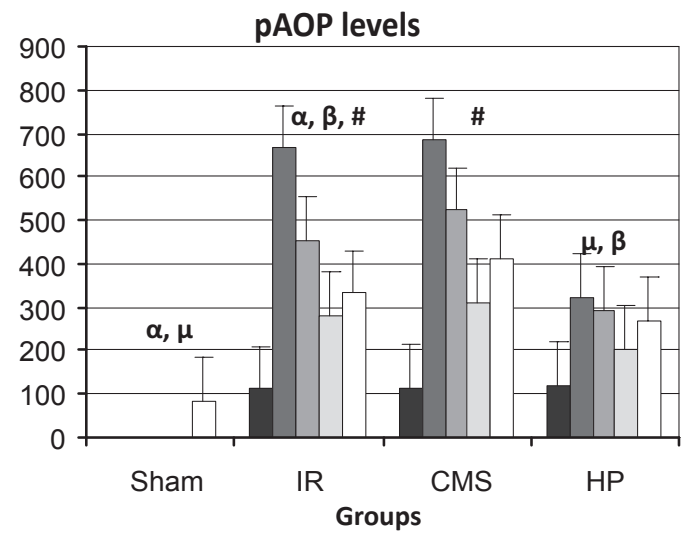

घ Preisch $\square$ 1st hour $\square$ 2nd hour $\square$ 4th hour $\square$ Mean $\alpha: p=0.002 \quad \mu: p=0.07 \quad \beta: p=0.4 \quad \#: p=0.1$

(The difference between the levels of pAOP on the 1st and 2nd hour of IR and HP was significant $\mathrm{p}=0.001$ )

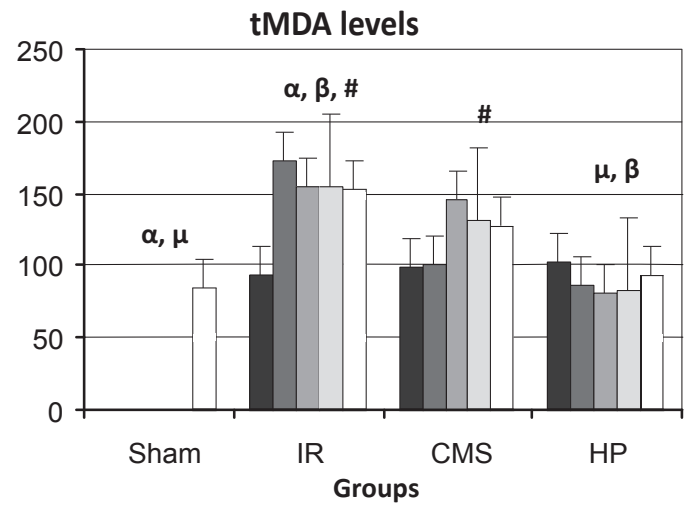

- Preisch $\square$ 1st hour $\square$ 2nd hour $\square$ 4th hour $\square$ Mean $\alpha: p=0.001 \quad \mu: p=0.66 \quad \beta: p=0.001 \quad \#: p=0.07$

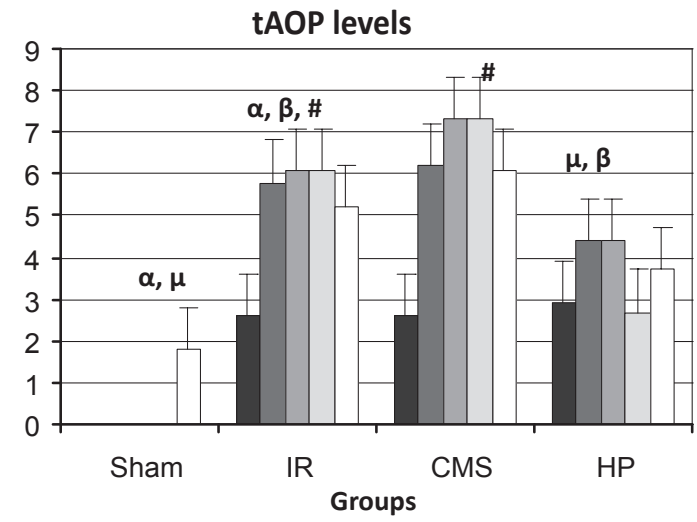

- Preisch $\square$ 1sthour $\square$ 2nd hour $\square$ 4th hour $\square$ Mean $\alpha: p=0.001 \quad \mu: p=0.01 \quad \beta: p=0.004 \quad \#: p=0.12$

Fig. 3. The levels of LDH on different reperfusion hours were given. Comparison of mean levels of LDH and number PMNL per unit area among groups were shown (p values used for comparison of groups were pointed by $\alpha, \beta, \#, \mu$ ). 

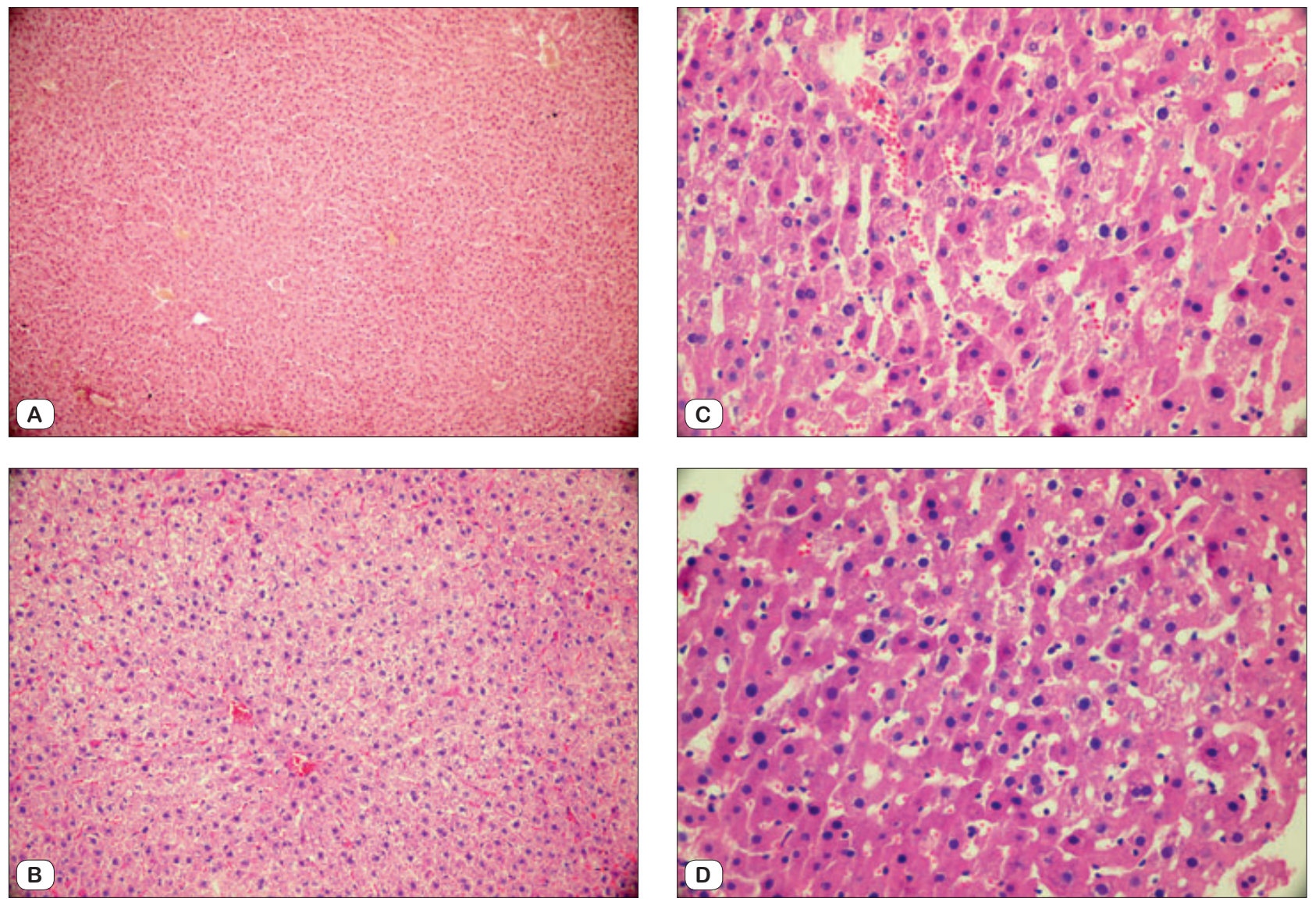

Fig. 4. Histopathologic appereances of liver tissues among groups. High grade liver injuries were seen in group IR and CMS. Normal appereance was seen in sham group. Low grade liver injury was seen in HP group. a) Histopathologic appereance of liver samples in sham group. Neither injury nor PMNL infiltration is seen $(H \& E$ X100), b) Histopathologic appereance of liver samples in control group. Grade-2 injury and PMNL infiltration is seen (H\&E X400), c) Histopathologic view of liver samples in CMS group. Grade-2 injury and PMNL infiltration are seen (H\&E X200), d) Histopathologic view of liver samples in HP group. Grade-1 injury and minimal PMNL infiltration are seen (H\&E X400).

\section{Discussion}

In our study, addition of HP and CMS to the diet didn't have unfavorable effect on liver function test. However it was shown that HP has hepatoprotective role in hepatic I/R through antioxidative and antiinflammatory effect. An excessive production of oxygen free radicals, arachidonic acid metabolites and leukocyte migration and activation, neutrophil infiltration, tumor necrosis factor, and Kupffer cell activation have been reported in ischemic reperfused liver, leading to tissue damage. This is an unavoidable process in liver transplantation and in the surgical procedures in which the Pringle maneuver is used (4). For this reason several free radical scavengers have been used in reducing hepatic I/R injury (5-7). Also I/R increases not only oxidative stress, but also modulates production of toxic cytokines leading to inflammation and leukocyte infiltration $(4,17)$. The inflammatory process which starts locally becomes systemic action by inflammatory cytokines and circulating oxygen radicals. In our study IR has resulted in significant tissue injury, increased cytokine levels, liver enzymes, lipid peroxidation products and advanced oxydation protein products.
An interesting finding is that CMS neither showed additive inflammation nor injury. This agent is a suitable disolvent for HP. It has been showed that HP has antioxidant bioactivity $(9,12,18,22,23)$. Also previous studies have showed that HP attenuated the hepatotoxicity, hepatocyte peroxidation and improved the hepatitis (19). Our study showed that HP is hepatoprotective in experimental IR.

In our study, HP markedly attenuated ALT, AST an LDH activities which are used a marker of cellular damage following hepatic I/R injury. The increase of AST, ALT and LDH activities observed in $\mathrm{I} / \mathrm{R}$ and $\mathrm{CMS}$ groups can be elucidated by lipid peroxidation leading to cytolysis which is caused by oxygen free radicals formed during the reperfusion phase (20). This is the protective effect of HP on hepatocyte damage. Antioxidative integrients of HP found also in other hypericum species also showed hepatoprotective effects in various experimental hepatitis models and improved transaminase levels were seen in recent studies $(21,22)$. These effects of HP after IR may be due to protection of sinusoidal endothelial cells which are the first target and improvement of oxidative stres. Increased levels of liver enzymes indicating hepatocyte destruction were in corcordance with the histopathologic results. HP has 
eliminated the adverse effects of IR and produced similar levels of liver enzymes with the sham group.

Advanced oxidation protein products originate as a result of the action of free radicals on proteins and may act as inflammatory mediators triggering the oxidative "ignition" of neutrophils monocytes and T-lymphocytes. Furthermore HP demonstrated a free radical scavenging activity because they prevented a colored reaction produced by the horsedish peroxidase-catalysed formation of hydroxyl free radicals from hydrogen peroxide (24). In an another study, HP derivatives demonstrated a strong reduction in oxidative burst of polymorhonuclear cells after stimulation with $\mathrm{N}$-formyl-methionyl-leucyl-phenylalanine (22). HP derivatives including quercetin, rutin, flavonoids, hyperorsde, ialibinone are important free radical scavengers. The antiinflammatory effects of HP have been shown in previous studies $(25,26)$. AOP is not only a member of oxidative stres but also acts as an inflammatory mediator. In our study, HP showed hepatoprotective effect by decreasing tissue AOP levels. The mentioned mechanisms of protection included increasing intracellular GSH, directly lowering levels of ROD, and preventing the influx of Ca despite high levels of ROS. The oxidation products together with the activity of Kuppfer cells and inflammatory cells in liver were decreased by HP. HP has such an antioxidative capacity that there was no significant difference between tissue AOP levels of HP and sham groups. On the other hand mean plasma AOP levels showed no difference between IR and HP. However, the levels of plasma AOP in the IR group on the 1st and 2nd hour were significantly higher when compared with HP. It was seen in our study that HP has not only anti-oxidative role in tissue but also has immediate effect in plasma. But the protective effect wasn't so prominent within time when compared with IR group. However the decrease of plasma AOP in IR within time might be probably due to the anti-oxidation in other parts of body. However tissue AOP levels remained high in IR group probably due to the activated inflammatory cytokines from cells in liver. However, HP has managed to decrease this effect. The decrease in the levels of both TNF- $\alpha$ and IL- 6 was worth to note not even as significant as in the plasma AOP levels which might be due to the ongoing inflammatory response to liver tissue. Inflammatory activity which has arised from the liver could have been depressd by HP.

In the present study, the levels of MDA, which is the product of lipid peroxidation, were significantly increased by IR in both plasma and tissue. This observation was in agreement with previous studies where elevated levels of lipid peroxidation products were detected. HP treatment abolished the increase of lipid peroxidation products, probably in part by scavenging the very reactive oxidative products. An antioxidant activity of quercetin was also demonstrated by inhibition of brain lipid peroxidation, as manifested by lowering MDA while elevating phospholipid contents in a rat model of endotoxemia (27). In our study we evaluated not only the values of the tissue MDA but also the plasma MDA. Our results showed that HP is protective against both tissue and plasma lipid peroxidation. This may be due to decreased oxidative products in plasma. However, although the plasm AOP levels decreased within time the plasma MDA levels remained high in
IR group. This is probably due to continuing effect of liver injury on plasma lipid peroxidation. On the other hand HP significantly decreased the mean plasma MDA levels but not the plasma AOP levels. This made us to think that HP might have direct effect on plasma lipid peroxidation.

Moreover it has been shown that ischemia reperfusion increases oxidative stress, an effect that not only produces direct tissue damage, but also modulates production of toxic cytokines leading to inflammation and leukocyte infiltration (17). Growing evidence has clearly demonstrated that inhibition of ROS prevents the infiltration of neutrophils at inflammation sites (28). In traditional usage, HP is effective in wound healing. In several studies, it has been showed that HP has anti-inflammatory effect leading to improved wound healing (10). In our study, we found increased histopathological injury and polymorphonuclear leukocyte infiltration in liver tissue in IR. However, HP decreased infiltration significantly. The increased inflammatory cells activated by oxidative stress which occured after reperfusion injury have produced inflammatory cytokines such as TNF- $\alpha$, IL-6. As in our study, inflammatory cytokines and cells were significantly decreased by HP treatment. In a previous study, HP has been demonstrated to reduce morphological injury and neutrophil infiltration (8). In that report, the reason for decreased neutrophil infiltration by HP has been explained by lowered productions of TNF- $\alpha$ and IL-1 $\beta$. Similarly our study pointed the protective role of HP on hepatocyte morphology probably due to the inhibition of TNF- $\alpha$ and IL- 6 . Similarly HP showed inhibition of IL-12 in activated macrophages in the study of Kang BY et al (29). Antiinflammatory effects of HP is shown in our study also. The mechanism mentioned in previous studies was NF-kB. HP significantly reduces the NF-kB translocation $(30,31)$. Morever, it was demonstrated that HP treatment also inhibits the IkB- $\alpha$ degredation. NF-kb plays a central role in the regulation of many genes responsible for the cytokines including TNF- $\alpha$ and IL- $1 \beta$ which has role in propagating the extension of a local and systemic inflammatory process $(30,31)$. However the exact mechanisms by which HP supress NF-kB activation are not known exactly.

Apoptosis of hepatocytes and sinusoidal endothelial cells form critical mechanism in hepatic IR. The mechanism of injury depends on production of oxygen radical species and intracellular overloading. Translocation of bacteria from gut and TNF- $\alpha$ induction from neutrophils induce hepatocyte apoptosis. Hypericum perforatum which comprises several antioxidative substances has succesfully diminished the hepatocyte injury in our experimental model of hepatic IR injury. The possible mechanism might be that the antioxidant property of HP can eliminate free radicals and inhibit neutrophil activation. Decreased inflammatory response protects the hepatocytes from destruction and less transamines leak into the blood. Hypericum perforatum showed its effect not only in liver but also in the plasma. Pointed mechanisms of HP in intracellular are NF-kB, intracellular GSH, Ca metabolism and intracellular antioxidative elements. More studies about the mechanism of HP are needed.

In conclusion, this study provides evidence that $H$. perforatum extracts which have been used for wound healing, depres- 
sion, hepatotoxicity, burns, epilepsy until ancient times, caused a substantial reduction of liver ischemia/reperfusion injury in rats. H. perforatum extracts which can be used orally have hepatoprotective roles by anti-oxidative actions.

\section{References}

1. Van Gulik TM, De Graaf W, Dinant S, Busch OR, Gouma DJ. Vascular occlusion techniques during liver resection. Dig Surg 2007; 24 (4): 274-281.

2. Walsh KB, Toledo AH, Rivera-Chavez A, Lopez-Neblina F, ToledoPereyra LH. Inflammatory mediators of liver ischemia-reperfusion injury. Exp Clin Transplant 2009; 7 (2): 78-93.

3. Inglot FR, Habib NA, Mathie RT. Hepatic ischemia- reperfusion injury. Am J Surg 2001; 181 (2): 160-166.

4. Teoh NC, Farell GC. Hepatic ischemia reperfusion injury: pathogenic mechanisms and basis for hepatoprotection. J Gastroenterol Hepatol 2003; 18 (8): 891-902.

5. Kucuk C, Akcan A, Akyildiz H, Akgün H, Muhtaroğlu S, Sozuer E. Effects of Amrinone in an experimental model of hepatic ischemia-reperfusion injury. J Surg Res 2009; 151 (1): 74-79.

6. Yildiz F, Coban S, Terzi A et al. Nigella sativa relieves the deterious effects of ischemia reperfusion injury on liver. World J Gasterol. 2008; 14 (33): 5204-5209.

7. Polat KY, Aydinli B, Polat $O$ et al. The protective effect of aprotinin and alpha-tocopherol on ischemia-reperfusion in jury of the rat liver. Transplant Proc 2008; 40 (1): 63-68.

8. De Paola R, MMuia C, Mazzon E et al. Effects of hypericum perforatum extract in a rat model of ischemia and reperfusion injury. Shock 2005; 24 (3): 255-263.

9. Saija A, Scalese M, Lanza M, Marzullo D, Bonina F, Castelli F. Flavonoids as antioxidant agents: importance of their interaction with biomembrane. Free Radical Bil Med 1995; 19 (4): 481-486.

10. Dost T, Ozkayran H, Gokalp F, Yenisey C, Birincioğlu M. The effect of Hypericum perforatum (St. John's Wort) on experimental colitis in rat. Dig Dis Sci 2009; 54 (6): 1214-1221.

11. Ozturk B, Apaydin S, Goldeli E, Ince I, Zeybek U. Hypericum triquetrifolium tura extract exhibits antiinflammatory activity in the rat. J Ethnopharmacol 2002; 80 (2): 207-209.

12. Yang SY, Juang SH, Tsai SY, Chao PD, Hou YC. St. John's wort significantly increased the systemic exposure and toxicity of methotrexate in rats. Toxicol Appl Pharmacol 2012; 263 (1): 39-43.

13. Kerem M, Bedirli A, Pasaoğlu $\mathbf{H}$ et al. Effect of adrenomedullin on hepatic damage in hepatic ischaemia/reperfusion injury in rats. Liver Int 2008; 28 (7): 972-981.

14. Okhawa H, Ohishi N, Yagi K. Assay for lipid peroxides in animal tissues by thiobarbituric acid reaction. Anal Biochem 1979; 95 (2): 351-358.

15. Yoshioka T, Kawada K, Shimada T, Mori M. Lipid peroxidation in maternal and cord blood and protective mechanism against activated-oxygen toxicity in the blood. Am J Obstet Gynecol 1979; 135 (3): 372-376.
16. Witko-Sarsat V, Friedlander M, Capeillere-Blandin C et al. Advanced oxidation protein products as novel marker of oxidative stres in üremia. Kidney International 1996; 49 (5): 1304-1314.

17. Sözen S, Kisakürek M, Yildiz F, Gönültas M, Dincel AS. The effects of glutamine on hepatic ischemia reperfusion injury in rats. Hippokratia 2011; 15 (2): 161-166.

18. Hosni K, Msaada K, Ben Taarit M, Chahed T, Marzouk B. Volatile constituents of two Hypericum species from Tunisia. Nat Prod Commun 2011; 6 (11): 1731-1734.

19. Ekin S, Oto G, Yardim Y, Levent A, Ozgokce F, Kusman T. Protective effect of Hypericum perforatum L. on serum and hair trace elements in rats 7,12-dimethylbenz(a)anthracene-induced oxidative stress. Environ Toxicol Pharmacol 2012; 33 (3): 440-445.

20. Chouker A, Martignoni A, Schauer RJ et al. Alpa-gluthathione Stransferase as an early marker of hepatic ischemia/reperfusion injury after liver resection. World J Surg 2005; 29 (4): 528-534.

21. Wang N, Wang Y, Peng Wei et al. Hepatoprotective effect of hypericum japonicum extract and its fractions. J Ethnopharmacology 2008; 116 (1): $1-6$.

22. Heilmann J, Winkelmann K, Sticher O. Studies on the antioxidative of phloroglucinol derivatives isolated from Hypericum species. Planta Med 2003; 69 (3): 202-206.

23. Benedi J, Arroya R, Romero $\mathbf{C}$ et al. Antioxidant properties and protective effects of a standart extract of Hypericum perforatum on hydrogen peroxide-induced oxidative damage in PC12 cells. Life Sci 2004; 75 (10): 1263-1276.

24. Sloley BD, Urichuk LJ. Chemical and pharmacological evaluation of hypericum perforatum extracts. Acta Pharmacol Sin 2000; 21 (12): $1145-1152$.

25. Chung MI, Weng JR, Wang JP, Teng CM, Lin CN. Antiplatelet and anti-inflammatory constituents and new oxygenated xanthones from Hypericum geminiflorum. Planta Med 2002; 68 (1): 25-29.

26. Kumar V, Singh PN, Bhattacharya SK. Anti-inflammatory activity of Indian hypericum perforatum L. Indian J Exp Biol 2001; 39 (4): 339-343.

27. Heilmann J, Winkelmann K, Sticher O. Studies on the antioxidative activity of phloroglucinol derivatives isolated from hypericum species. Plant Med 2003; 69 (3): 202-206.

28. Abd El-Gawad HM, Khalifa AE. Quercetin, coenzyme Q10 and L-canavanine as protective agents against lipid peroxidation and nitric axide generation in endotoxin-induced shock in rat brain. Pharmacol Res 2001; 43 (3): 257-263.

29. Kang BY, Chung SW, Kim TS. Inhibition of interleukin-12 production in lipopolysaccharide-activated Mouse macrophages by hypericin, an active component of Hypericum perforatum. Planta Med 2001; 67 (4): 364-366.

30. Bork PM, Bacher S, Schmitz ML, Kaspers U, Heinrich M. . Hypericum as a non-oxidant inhibitor of NF-kappa B. Planta Med 1999; 65 (4): 297-300.

31. Paterniti I, Briguglio E, Mazzon E, et al. Effects of Hypericum Perforatum, in a rodent model of periodonititi. BMC Complement Altern Med 2010; 10:73. 